\title{
Route of Nicotine Administration Influences In Vivo Dopamine Neuron Activity: Habituation, Needle Injection, and Cannula Infusion
}

\author{
Yu Dong, \\ Department of Neuroscience, Baylor College of Medicine, Houston, TX 77030-3498, USA \\ Tianxiang Zhang, \\ Department of Neuroscience, Baylor College of Medicine, Houston, TX 77030-3498, USA \\ Wei Li, \\ Department of Neuroscience, Baylor College of Medicine, Houston, TX 77030-3498, USA \\ William Doyon, and \\ Department of Neuroscience, Baylor College of Medicine, Houston, TX 77030-3498, USA
}

John A. Dani

Menninger Department of Psychiatry and Behavioral Sciences, Baylor College of Medicine, Houston, TX 77030, USA; Department of Neuroscience, Baylor College of Medicine, Houston, TX 77030-3498, USA

\begin{abstract}
Mesolimbic dopamine (DA) systems play a critical role in tobacco addiction driven by nicotine. Nicotine activates midbrain DA neurons and, consequently, elevates DA concentrations in targets, especially in the nucleus accumbens (NAc) of the ventral striatum. The route of drug administration influences the impact of addictive drugs. Here, we examine whether the nature of the administration alters DA neuron activity and DA concentrations in the NAc. Using unhabituated naïve freely moving rats, microdialysis measurements showed that nicotine administered via needle injection caused greater DA release in the NAc than the same dose administered via an implanted chronic cannula. After habituation to the needle injections, however, there was no significant difference in DA signaling between the needle and cannula routes of administration. Consistent with these microdialysis results after habituation, our in vivo tetrode unit recordings showed no significant difference in midbrain DA neuron activity in response to nicotine delivered by needle or cannula as long as predictive cues were avoided.
\end{abstract}

\section{Keywords}

Ventral tegmental area; Substantia nigra; Striatum; Nucleus accumbens; Tetrodes; Microdialysis

\footnotetext{
(C) Humana Press 2009

jdani@bcm.tmc.edu .

Yu Dong and Tianxiang Zhang contributed equally to this work.

Proceedings of the XIII International Symposium on Cholinergic Mechanisms
} 


\section{Introduction}

Despite tobacco use being a major health problem, there are about one billion tobacco smokers worldwide (Dani and Harris 2005; Mathers and Loncar 2006; Crane 2007; Benowitz 2008). More than $20 \%$ of American adults smoke, and consequently, there are about 400,000 deaths per year caused by direct cigarette use in the United States. Most users would like to quit smoking, but there is a high rate of relapse among individuals who try to quit. About a third of the smokers try to stop each year, but less than 3\% succeed (Centers for Disease Control and Prevention (CDC) 2005; Crane 2007).

Nicotine is the main addictive component of tobacco based on its ability to support selfadministration and drug-seeking behavior in animals under controlled laboratory conditions (Corrigall and Coen 1989; Stolerman and Shoaib 1991; Corrigall 1999; Karan et al. 2003). Nicotine also increases locomotor activity, enhances reward from brain stimulation, and reinforces place preference, as seen with other addictive drugs (Clarke 1991; Stolerman and Shoaib 1991; Dani and Heinemann 1996; Corrigall 1999; Di Chiara 2000). Furthermore, nicotine cessation produces a withdrawal syndrome, and those symptoms can be relieved by nicotine replacement (Stolerman and Jarvis 1995; Salas et al. 2004).

Midbrain dopaminergic systems serve an important role in the initiation of drug addiction, and that situation applies for nicotine as obtained from tobacco. Initial nicotine administrations increase dopamine (DA) concentration, as measured by microdialysis in the nucleus accumbens (NAc) of the ventral striatum (Pontieri et al. 1996; Balfour et al. 2000; Di Chiara 2000; Balfour 2004; Pidoplichko et al. 2004). The role of the midbrain DA systems in nicotine addiction is supported by the findings that DA antagonists or lesions of DA neurons reduce self-administration (Corrigall and Coen 1989; Corrigall et al. 1992; Corrigall 1999; Di Chiara 2000). By acting at nicotinic acetylcholine receptors (nAChRs), nicotine can activate neurons of the ventral tegmental area (VTA) and the substantia nigra pars compacta (SNc) and cause DA release in the striatum, particularly the NAc (Clarke et al. 1985; Grenhoff et al. 1986; Calabresi et al. 1989; Clarke 1991; Nisell et al. 1994; Pontieri et al. 1996; Pidoplichko et al. 1997; Picciotto et al. 1998; Dani et al. 2001; Mansvelder and McGehee 2002). Furthermore, presynaptically located $\mathrm{nAChRs}$ in the targets of the dopaminergic projections potently regulate DA release, as has been investigated in the dorsal striatum and NAc (Wonnacott et al. 2000; Jones et al. 2001; Zhou et al. 2001; Rice and Cragg 2004; Salminen et al. 2004; Zhang and Sulzer 2004; Grady et al. 2007).

The biological route of drug administration influences the dose, kinetics, metabolism, DA signaling, and the reported "high" or drug liking (Volkow et al. 2000). Therefore, it is not surprising that the route of administration influences the reinforcing impact and the addictive liability of a drug. For instance, cocaine has greater abuse potential when it is smoked or administered by the intravenous route than by the intranasal route (Hatsukami and Fischman 1996; Volkow et al. 2000). It is intriguing, however, that different routes of administration of similar doses that produce similar cocaine plasma concentrations and similar influences over aspects of DA signaling can produce different behavioral effects and reports of "high" (Volkow et al. 2000).

In animal studies, drug administration is precisely controlled and often administered by injection using a syringe and needle. The question we ask in this study is the following: does the pain or cue associated with the injection alter DA neuron unit firing in the midbrain (as measured by in vivo tetrode recordings) or alter DA release in the NAc (as measured by in vivo microdialysis)? Furthermore, does habituation to the injections diminish the effect of the needle injection? The results of these tests can aid in the design of laboratory experiments, and they also address several issues regarding dopaminergic systems. 
Some theories about the function of dopaminergic signaling emphasize the involvement of the expectation in the response to natural rewards or reinforcing drugs (Schultz et al. 1997; Robinson and Berridge 2000; Bayer and Glimcher 2005; Schultz 2006). However, dopaminergic systems also respond to aversive events, emotional stressors, and aspects of pain (Horvitz 2000; Pruessner et al. 2004; Scott et al. 2006). Therefore, most recent theories of DA signaling recognize a role for DA beyond simply reinforcing rewarding behaviors.

In the present study in which we use naïve freely moving rats, we show by microdialysis that nicotine administered via intraperitoneal needle injection (i.p.) causes greater DA release in the NAc than the same dose administered i.p. via an indwelling chronic cannula. However, after habituation to the needle injections, there is no significant difference in DA signaling between the needle and cannula routes of administration. Consistent with these microdialysis results after habituation, our in vivo tetrode unit recordings show no significant difference in midbrain DA neuron firing rates in response to nicotine between the needle and cannula administration routes. This result and conclusions require, however, that there are no cues that the rats can consistently use to predict the nicotine administration.

\section{Experimental Procedures}

\section{Animal Care and General Procedures}

For all the studies, male Long-Evans rats (Harlan, Indianapolis, IN, USA) were used at a weight of 295-365 g. They were housed with food and water available ad libitum and were kept on a 12/12-h light/dark schedule and tested in the light phase. Surgeries were conducted following the guidelines of the National Institutes of Health and Baylor College of Medicine. Rats were initially anesthetized by injecting (i.p.) a xylazine, ketamine, and acepromazine mixture. Then the rats were placed in a stereotaxic apparatus where anesthesia was controlled by isoflurane inhalation. The body temperature was maintained with a thermostatically controlled heating blanket.

The chronic cannula was surgically implanted to administer solutions i.p. to match the i.p. needle injections. With the cannula, nicotine was administered to minimize handling and the pain of the needle, but some cues were still present including the entry of the same amount of fluid with or without nicotine. The cannula was flushed with saline $(1.0 \mathrm{ml} / \mathrm{kg})$ regularly after implantation, and this process may have helped break the link between fluid infusion and a nicotine dose.

Rats that were habituated to injections of saline with a needle were given two injections a day for 5 days. The microdialysis experiments were conducted the next day, but the in vivo recordings with tetrodes were conducted over many days. During those days of recording, when new units were isolated, the rat was injected with nicotine to determine its effect and injected by quinpirole and eticlopride to help identify the units as dopaminergic neurons. Therefore, rats used for unit recording either received nicotine by an implanted cannula (in which case they did not receive injections) or they where habituated to the needle injections.

\section{In Vivo Microdialysis and Dopamine Quantification}

The microdialysis CMA/12 guide cannula (CMA/Microdialysis, Solna, Sweden) was aimed at the NAc (1.7 mm AP; $0.8 \mathrm{~mm} \mathrm{~L} ; 6.5 \mathrm{~mm}$ DV). On the day preceding the test session, CMA/ 12 microdialysis probes (inner diameter, $0.5 \mathrm{~mm}$; length, $2 \mathrm{~mm}$; membrane, polycarbonate; cutoff, 20,000 Da) were perfused with artificial cerebral spinal fluid (149 mM NaCl, $2.8 \mathrm{mM}$ $\mathrm{KCl}, 1.2 \mathrm{mM} \mathrm{CaCl}_{2}, 1.2 \mathrm{mM} \mathrm{MgCl}_{2}$, and $0.25 \mathrm{mM}$ ascorbic acid, $5.4 \mathrm{mM}_{\mathrm{D}}$-glucose). At least $14 \mathrm{~h}$ before the experiment, we lowered the probes slowly into the brain through the guide cannula while the rat was briefly anesthetized (10-15 min) with $2 \%$ isoflurane. The perfusion 
flow rate was decreased to $0.5 \mu \mathrm{l} / \mathrm{min}$ overnight and then increased to $2.0 \mu \mathrm{l} / \mathrm{min}$ at least $1 \mathrm{~h}$ prior to baseline sampling. Each sample vial was manually changed and immediately stored at $-80^{\circ} \mathrm{C}$ until analyzed. After these experiments, rats were killed with an overdose of anesthetics and transcardially perfused with phosphate-buffered saline and then fixed with $10 \%$ formalin. The accuracy of probe placement (Fig. 1) was confirmed by histological sectioning.

The DA content of microdialysates was determined using a high-performance liquid chromatography system based on reversed-phase chromatography with electrochemical detection. The system included a pump (Model 582; ESA, Chelmsford, MA, USA), an autosampler (Model 542; ESA), and a HR-3.2×80 mm column (3- $\mu \mathrm{m}$ particle size; ESA). A 5014B coulometric cell (ESA) was connected to an ESA Coulochem II detector. The mobile phase contained citric acid $(4.0 \mathrm{mM})$, sodium dodecyl sulfate $(3.3 \mathrm{mM})$, sodium dihydrogen phosphate dehydrate $(100.0 \mathrm{mM})$, ethylenediaminetetraacetic acid $(0.25 \mathrm{mM})$, acetonitrile $(15 \%)$, and methanol (5\%). The autosampler mixed $27 \mu \mathrm{l}$ of the dialysate with ascorbate oxidase (EC 1.10.3.3; $162 \mathrm{U} / \mathrm{mg}$; Sigma-Aldrich, St. Louis, MO, USA) prior to injection. Quantification of dialysate DA concentration was carried out by comparing peaks to external standards $(0-2 \mathrm{nM})$.

\section{Unit Recordings from Midbrain DA Neurons Using Chronic In Vivo Tetrode Electrodes}

A tetrode microdrive containing 12 tetrodes was attached to a rat's skull with screws and dental cement and aimed toward the VTA and adjacent SNc at AP, $-5.5 \mathrm{~mm}$ and ML, $1.1 \mathrm{~mm}$ from bregma. The tetrodes were positioned into the midbrain DA area $(7.5-9 \mathrm{~mm}$ beneath the surface of the neocortex), and the electrical signals were recorded (Cheetah System, Neuralynx, Tucson, AZ, USA). Recordings were digitized gap-free at 26.5 or $40 \mathrm{kHz}$ after variable lowpass and high-pass filtering, saved on computer disk, and analyzed offline where versatile digital filtering was applied.

Spikes were identified and extracted in Matlab (Xtractor by M. Krause and W. Li). Individual unit isolation was achieved based on the relative amplitudes of their action potentials on the four channels of a tetrode in combination with spike waveform parameters (action potential duration, waveform shape). This spike-sorting procedure was accomplished using in-house software and software developed by Dr. A. David Redish (MClust).

A neuron was classified as dopaminergic based on the following electrophysiological criteria: low baseline firing rate (0.5-8 Hz; Ungless et al. 2004; Anstrom and Woodward 2005), long spike duration (>1.5 ms, which is dependent on filter settings), and no spikes within the first $2 \mathrm{~ms}$ of the interspike interval (Wang 1981). Pharmacological criteria indicative of DA neurons (Hyland et al. 2002; Robinson et al. 2004; Pan et al. 2008) required the firing rate to be strongly inhibited ( $>50 \%)$ by the $\mathrm{D}_{2}$-type receptor agonist quinpirole $(1.0 \mathrm{mg} / \mathrm{kg}$, i.p.), and this inhibition had to be reversed by the $\mathrm{D}_{2}$-type receptor antagonist eticlopride $(0.5-1 \mathrm{mg} / \mathrm{kg}$, i.p.). These conservative criteria, while ensuring that DA neurons are selected, will likely identify a subset of the more diverse DA neuron population of the midbrain. Postmortem histology confirmed that the electrodes were located in tyrosine hydroxylase positive regions of the VTA and SNc (Fig. 3a).

\section{Statistical Analysis}

DA levels (in nanomolars) from microdialysis and DA neuron firing rates (in Hertz) were analyzed using analysis of variance (ANOVA) with repeated measures. For the analysis of the microdialysis data, DA concentrations were log transformed to maintain homogeneity of variance. The average of the last three basal samples defined the baseline DA response, which we used to test between-subject and within-subject effects of the drug challenge. For the analysis of the firing rates, the four 3-min bins prior to the nicotine injection defined the baseline 
response. ANOVA was performed using the Manova in SPSS for Windows. Significance for all analyses was determined by $p<0.05$.

\section{Results}

\section{Route of Nicotine Administration Influences the Dopamine Signal Measured by Microdialysis}

A feature indicative of addictive drugs such as cocaine, amphetamine, and nicotine is that they increase the concentration of DA in the NAc (Di Chiara and Imperato 1988; Pontieri et al. 1996; Balfour et al. 2000; Di Chiara 2000). The placement of the microdialysis probe was in the NAc, and the placement always included the NAc shell (Fig. 1). We administered nicotine $(0.4 \mathrm{mg} / \mathrm{kg}$ ) under three conditions (Fig. $2 \mathrm{a}$ ): by i.p. injection into rats not habituated to needle injections ( $n=8$, diamonds), by i.p. injection into rats habituated to the needle injections ( $n=5$, open circles), and by an equivalent nicotine administration via a chronic indwelling i.p. cannula ( $n=10$, filled circles). Basal DA concentrations for the three groups were $0.6 \pm 0.2$

(unhabituated), $0.3 \pm 0.1 \mathrm{nM}$ (habituated), and $0.5 \pm 0.1 \mathrm{nM}$ (cannula) and were not statistically different (group $\times$ time: $F(4,40)=0.34, p>0.05$ ). When the nicotine response for each of the three routes of administration was compared to their own baseline, nicotine produced a significant increase in DA concentration: unhabituated (time: $F(9,63)=28.15, p<0.05$ ), habituated (time: $F(9,36)=9.68, p<0.05)$, cannula (time: $F(9,81)=5.48, p<0.05)$.

A between-group comparison showed that the nicotine-induced DA signal in unhabituated rats was significantly greater and more prolonged than the habituated case (group $\times$ time: $F(9,99)$ $=2.40, p<0.05$ ) and the cannula case (group $\times$ time: $F(9,144)=2.02, p<0.05$ ).

However, the DA signals arising from injections into rats habituated to the needle were not statistically different from the DA signals arising from administration by cannula (Fig. 2a) (group $\times$ time: $F(9,117)=0.62, p>0.05$ ).

We used higher-resolution microdialysis sampling ( 5 min per sample) to detect a DA signal induced by the needle injection of saline (without nicotine) into unhabituated rats (Fig. 2b). While the DA signal was detectable, it did not produce a statistically significant change in the basal DA concentration, $n=5$ (time: $F(4,16)=1.87, p=0.17$ ). The DA response in the first sample following the saline injection ranged from $92 \%$ to $155 \%$ of basal, indicating the high variability, but this change was not significantly different than baseline (time: $F(1,4)=4.38, p=0.10$ ). These results collectively indicate that the pain or cue associated with administration of a neutral stimulus (i.e., saline) does not reliably influence NAc DA release (Fig. 2b), but it does when that injection is paired with a reinforcer, such as nicotine (Fig. 2a, unhabituated).

\section{Route of Nicotine Administration Influences Unit Firing by Dopamine Neurons}

To determine the influence the route of nicotine administration had over DA neuron firing rates, we placed tetrodes (Wilson and McNaughton 1994) chronically into the midbrain DA area of freely moving rats. At the end of each experiment, the recording locations were verified by lesions to be predominately in the VTA (Fig. 3a). Putative DA neurons were identified using the conservative criteria described in the Experimental Procedures. Because recording took place over many days, we studied rats that had an i.p. cannula or rats that were habituated to the needle injections.

The in vivo unit recording data were collected using the same timing and drug administration for rats with i.p. cannula and for those receiving i.p. injections. The average time course of the data obtained with habituated rats that received i.p. injections is shown in Fig. 3b. The mean baseline DA firing rates were $4.1 \pm 0.4 \mathrm{~Hz}$ ( $n=19$ units). When nicotine was injected, the firing rate increased relatively quickly and remained elevated during the subsequent $1 \mathrm{~h}$ of recording (Fig. 3b, open circles). The relatively large error in the first data point after nicotine injection 
reflects that only two of the 19 units gave a noticeable increase in firing in response to the needle injection. DA neurons express $\mathrm{D}_{2}$-type receptors, and we required that putative $\mathrm{DA}$ neurons used in the average were robustly inhibited by the $\mathrm{D}_{2}$-type agonist, quinpirole, and activated by the $\mathrm{D}_{2}$-type antagonist, eticlopride (Fig. 3b; Grace and Bunney 1985;Centonze et al. 2002; Hyland et al. 2002; Robinson et al. 2004).

Equivalent unit recordings were collected from freely moving rats implanted with chronic i.p. cannula to administer an equivalent nicotine dose without the handling-related stress associated with needle injections. The average time course of the data is shown in Fig. $3 b$ (filled circles). The baseline firing rates $(3.7 \pm 0.2 \mathrm{~Hz}, n=17$ units) were similar to those obtained in the habituated group. The nicotine administered by cannula elicited a very similar increase in firing rate, and the overall time course was not statistically different between the two routes of nicotine administration (group: $F(1,34)=0.69, p>0.05$; group $\times$ time: $F(22,748)=0.58, p>0.05$ ). The lack of a difference between the groups is consistent with our microdialysis measurements of DA release and further suggests that the stimulus associated with needle administration of nicotine is diminished in animals habituated to the injection procedure.

\section{Discussion}

In summary, the results show that a needle injection of saline given to a naïve rat can produce a detectable, but not significant, DA response measured by microdialysis (Fig. 2b). However, if the needle injection results in the administration of nicotine, which is capable of stimulating DA transmission (Pontieri et al. 1996;Balfour et al. 2000;Di Chiara 2000;Balfour

2004;Pidoplichko et al. 2004), then a naïve rat experiencing the needle injection will respond with a statistically greater DA signal than a habituated rat or a rat receiving nicotine by cannula administration (Fig. 2a). On the other hand, a habituated rat or a rat with a cannula will respond to the same nicotine administration with DA responses that are statistically indistinguishable under our experimental conditions. Those microdialysis results were consistent with the results obtained by in vivo unit recordings with tetrodes (Fig. 3b). Rats habituated to needle injections showed more variable unit activity at the moment of nicotine injection, but the change in the DA neuron firing rates over time was statistically the same as the change seen in rats receiving the nicotine administration by cannula. Overall, this study quantitatively supports the conclusion that habituation to needle injections results in similar DA release and neuronal firing, whether nicotine is administered by needle injection or by cannula. For unhabituated naïve rats, these results also suggest that the pain or cue associated with needle injection of saline (a neutral stimulus) does not reliably alter NAc DA release, but it does so when that injection is paired with the reinforcing stimulus of nicotine. Despite that conclusion based on the statistical analysis of the data, the pain or cue associated with the needle injection of saline could occasionally produce a detectable DA signal (Fig. 2b). Furthermore, linking the needle or other cue to the nicotine-related reward was able to create a DA signal associated with the predictive cue (i.e., the needle injection), but that property was not the focus or purpose of this study.

\section{Dopamine Signals Induced by Nonrewarding, Stress, or Aversive Stimuli}

There is controversy about DA signaling arising from aversive stimuli. The more traditional modern view is that DA neurons respond to rewards or the expectation of reward (Schultz et al. 1997; Schultz 2001; Bayer and Glimcher 2005). In that way, mesolimbic DA systems participate to encode the reward value and the uncertainty of the reward. This process occurs within the course of learning that shapes and reinforces rewarding behaviors (Volkow et al. 2002; Wise 2004; Hyman et al. 2006; Dani and Montague 2007).

There are a number of studies, however, that have also observed DA signaling during nonrewarding events. Microdialysis and voltammetry measurements have shown increased 
DA in target areas in response to stress and aversive stimuli (Keefe et al. 1993; Horvitz 2000; Kienast et al. 2008). Studies in humans have supported the view that psychological stress can evoke DA release (Pruessner et al. 2004), supporting a role for DA beyond processing reward and cues related to reward. Experiments using positron emission tomography with radioactive raclopride (a DA D2-type receptor antagonist) showed that psychological stress produces significant DA release in the ventral striatum, particularly in those humans most vulnerable to stress (Pruessner et al. 2004). In addition, human studies indicate a striatal DA response to salient emotional and stressful aspects of pain (Horvitz 2000; Scott et al. 2006). Studies such as those suggested that DA signaling within the basal ganglia was responding to both the positive and negative saliency of events, thereby participating in the most appropriate subsequent behavioral reaction (Horvitz 2000; Pani et al. 2000; Pruessner et al. 2004; Scott et al. 2006; Kienast et al. 2008).

In addition to DA increases observed in the striatum, DA signaling in the amygdala has been implicated in processing the emotional impact and saliency of stressful and aversive stimuli (Rosenkranz and Grace 2002; Kienast et al. 2008). For example, the synaptic changes in the lateral nucleus of the amygdala that underlie learning the association between an odor and a foot shock required intact DA signaling (Rosenkranz and Grace 2002).

Stress and aversive stimuli have routinely produced increased DA concentrations as measured in target areas, but the firing of DA neurons as measured by in vivo unit recordings in the midbrain has been more variable. Restraint stress was shown to increase the firing of all 23 putative DA neurons measured from awake rats (Anstrom and Woodward 2005). More commonly, however, the response of the DA neurons is variable, with some putative DA neurons firing more, some less, and some unchanged (Chiodo et al. 1980; Schultz and Romo 1987; Horvitz 2000). Our anecdotal results obtained immediately after needle injections matched these variable results, with some neurons showing no change or depression, but we did observe an increased firing rate from a minority of putative DA neurons. Others, however, have found that DA neurons only rarely increase firing to aversive stimuli, with depressed firing being more common (Mirenowicz and Schultz 1996; Schultz 2007). Finally, one study concluded that presumed DA neurons that were excited by adverse stimuli were actually not dopaminergic (Ungless et al. 2004). In that study, however, the relatively small sample may not have included DA neurons that are excited by aversive stimuli.

\section{General Conclusion}

The present literature and our results obtained in this study seem to be in concordance. It is reasonable to conclude at this time that highly salient nonrewarding stimuli, including aversive events, are capable of producing DA signals, albeit, those signals are often slower and smaller in magnitude. Furthermore, our study indicates that habituation to a noxious stimuli (i.e., the needle injection) can diminish the consequent DA signal. Arguably the habituation process is removing the salience of the noxious stimuli. While the initial exposures to the painful stress of the needle injection would appear highly salient and possibly life threatening, many such exposures would produce learning in pertinent animals that the injections are transient and not permanently harmful. The most concrete conclusion of this study is that careful habituation that avoids linking a cue to a reward can reduce the DA signal arising from handling and needle injections to an insignificant value. These results should aid in the design of experiments.

\section{Acknowledgments}

This work was supported by grants from the National Institute on Drug Abuse (DA009411) and the National Institute of Neurological Disorders and Stroke (NS021229). 


\section{References}

Anstrom KK, Woodward DJ. Restraint increases dopaminergic burst firing in awake rats. Neuropsychopharmacology 2005;30:1832-1840. [PubMed: 15886724]

Balfour DJ. The neurobiology of tobacco dependence: a preclinical perspective on the role of the dopamine projections to the nucleus. Nicotine \& Tobacco Research 2004;6:899-912. [PubMed: 15801566]

Balfour DJ, Wright AE, Benwell ME, Birrell CE. The putative role of extra-synaptic mesolimbic dopamine in the neurobiology of nicotine dependence. Behavioural Brain Research 2000;113:73-83. [PubMed: 10942034]

Bayer HM, Glimcher PW. Midbrain dopamine neurons encode a quantitative reward prediction error signal. Neuron 2005;47:129-141. [PubMed: 15996553]

Benowitz NL. Clinical pharmacology of nicotine: Implications for understanding, preventing, and treating tobacco addiction. Clinical Pharmacology and Therapeutics 2008;83:531-541. [PubMed: 18305452]

Calabresi P, Lacey MG, North RA. Nicotinic excitation of rat ventral tegmental neurones in vitro studied by intracellular recording. British Journal of Pharmacology 1989;98:135-140. [PubMed: 2804543]

Centers for Disease Control and Prevention (CDC). State-specific prevalence of cigarette smoking and quitting among adults-United States. MMWR. Morbidity and Mortality Weekly Report 2005;54:1124-1127. [PubMed: 16280970]

Centonze D, Usiello A, Gubellini P, Pisani A, Borrelli E, Bernardi G, et al. Dopamine D2 receptormediated inhibition of dopaminergic neurons in mice lacking D2L receptors. Neuropsychopharmacology 2002;27:723-726. [PubMed: 12431847]

Chiodo LA, Antelman SM, Caggiula AR, Lineberry CG. Sensory stimuli alter the discharge rate of dopamine (DA) neurons: Evidence for two functional types of DA cells in the substantia nigra. Brain Research 1980;189:544-549. [PubMed: 7370790]

Clarke PB. Nicotinic receptor blockade therapy and smoking cessation. British Journal of Addiction 1991;86:501-505. [PubMed: 1859912]

Clarke PB, Schwartz RD, Paul SM, Pert CB, Pert A. Nicotinic binding in rat brain: Autoradiographic comparison of $[3 \mathrm{H}]$ acetylcholine, [3H]nicotine, and [125I]-alphabungarotoxin. Journal of Neuroscience 1985;5:1307-1315. [PubMed: 3998824]

Corrigall WA. Nicotine self-administration in animals as a dependence model. Nicotine \& Tobacco Research 1999;1:11-20. [PubMed: 11072385]

Corrigall WA, Coen KM. Nicotine maintains robust self-administration in rats on a limited-access schedule. Psychopharmacology (Berlin) 1989;99:473-478. [PubMed: 2594913]

Corrigall WA, Franklin KB, Coen KM, Clarke PB. The mesolimbic dopaminergic system is implicated in the reinforcing effects of nicotine. Psychopharmacology (Berlin) 1992;107:285-289. [PubMed: 1615127]

Crane R. The most addictive drug, the most deadly substance: Smoking cessation tactics for the busy clinician. Primary Care 2007;34:117-135. [PubMed: 17481990]

Dani JA, Harris RA. Nicotine addiction and comorbidity with alcohol abuse and mental illness. Nature Neuroscience 2005;8:1465-1470.

Dani JA, Heinemann S. Molecular and cellular aspects of nicotine abuse. Neuron 1996;16:905-908. [PubMed: 8630247]

Dani JA, Montague PR. Disrupting addiction through the loss of drug-associated internal states. Nature Neuroscience 2007;10:403-404.

Dani JA, Ji D, Zhou FM. Synaptic plasticity and nicotine addiction. Neuron 2001;31:349-352. [PubMed: 11516393]

Di Chiara G. Role of dopamine in the behavioural actions of nicotine related to addiction. European Journal of Pharmacology 2000;393:295-314. [PubMed: 10771025]

Di Chiara G, Imperato A. Drugs abused by humans preferentially increase synaptic dopamine concentrations in the mesolimbic system of freely moving rats. Proceedings of the National Academy of Sciences of the United States of America 1988;85:5274-5278. [PubMed: 2899326] 
Grace AA, Bunney BS. Low doses of apomorphine elicit two opposing influences on dopamine cell electrophysiology. Brain Research 1985;333:285-298. [PubMed: 3995296]

Grady SR, Salminen O, Laverty DC, Whiteaker P, McIntosh JM, Collins AC, et al. The subtypes of nicotinic acetylcholine receptors on dopaminergic terminals of mouse striatum. Biochemical Pharmacology 2007;74:1235-1246. [PubMed: 17825262]

Grenhoff J, Aston-Jones G, Svensson TH. Nicotinic effects on the firing pattern of midbrain dopamine neurons. Acta Physiologica Scandinavica 1986;128:351-358. [PubMed: 3788613]

Hatsukami DK, Fischman MW. Crack cocaine and cocaine hydrochloride. Are the differences myth or reality? Journal of the American Medical Association 1996;276:1580-1588. [PubMed: 8918856]

Horvitz JC. Mesolimbocortical and nigrostriatal dopamine responses to salient non-reward events. Neuroscience 2000;96:651-656. [PubMed: 10727783]

Hyland BI, Reynolds JN, Hay J, Perk CG, Miller R. Firing modes of midbrain dopamine cells in the freely moving rat. Neuroscience 2002;114:475-492. [PubMed: 12204216]

Hyman SE, Malenka RC, Nestler EJ. Neural mechanisms of addiction: The role of reward-related learning and memory. Annual Review of Neuroscience 2006;29:565-598.

Jones IW, Bolam JP, Wonnacott S. Presynaptic localisation of the nicotinic acetylcholine receptor beta2 subunit immunoreactivity in rat nigrostriatal dopaminergic neurones. The Journal of Comparative Neurology 2001;439:235-247. [PubMed: 11596051]

Karan, L.; Dani, JA.; Benowitz, N. The pharmacology of nicotine and tobacco. In: Graham, AW.; Schultz, TK.; Mayo-Smith, MF.; Ries, RK.; Wilford, BB., editors. Principles of addiction medicine. American Society of Addiction Medicine; Chevy Chase, Maryland, USA: 2003. p. 225-248.

Keefe KA, Sved AF, Zigmond MJ, Abercrombie ED. Stress-induced dopamine release in the neostriatum: evaluation of the role of action potentials in nigrostriatal dopamine neurons or local initiation by endogenous excitatory amino acids. Journal of Neurochemistry 1993;61:19431952.

Kienast T, Hariri AR, Schlagenhauf F, Wrase J, Sterzer P, Buchholz HG, et al. Dopamine in amygdala gates limbic processing of aversive stimuli in humans. Nature Neuroscience 2008;11:13811382.

Mansvelder HD, McGehee DS. Cellular and synaptic mechanisms of nicotine addiction. Journal of Neurobiology 2002;53:606-617. [PubMed: 12436424]

Mathers CD, Loncar D. Projections of global mortality and burden of disease from 2002 to 2030. PLoS Medicine 2006;3:e442. [PubMed: 17132052]

Mirenowicz J, Schultz W. Preferential activation of midbrain dopamine neurons by appetitive rather than aversive stimuli. Nature 1996;379:449-451. [PubMed: 8559249]

Nisell M, Nomikos GG, Svensson TH. Infusion of nicotine in the ventral tegmental area or the nucleus accumbens of the rat differentially affects accumbal dopamine release. Pharmacology and Toxicology 1994;75:348-352. [PubMed: 7534921]

Pan WX, Schmidt R, Wickens JR, Hyland BI. Tripartite mechanism of extinction suggested by dopamine neuron activity and temporal difference model. Journal of Neuroscience 2008;28:9619-9631. [PubMed: 18815248]

Pani L, Porcella A, Gessa GL. The role of stress in the pathophysiology of the dopaminergic system. Molecular Psychiatry 2000;5:14-21. [PubMed: 10673764]

Paxinos, G.; Watson, C. The rat brain in stereotaxic coordinates. Academic; San Diego: 1998.

Picciotto MR, Zoli M, Rimondini R, Lena C, Marubio LM, Pich EM, et al. Acetylcholine receptors containing the beta 2 subunit are involved in the reinforcing properties of nicotine. Nature 1998;391:173-177. [PubMed: 9428762]

Pidoplichko VI, DeBiasi M, Williams JT, Dani JA. Nicotine activates and desensitizes midbrain dopamine neurons. Nature 1997;390:401-404. [PubMed: 9389479]

Pidoplichko VI, Noguchi J, Areola OO, Liang Y, Peterson J, Zhang T, et al. Nicotinic cholinergic synaptic mechanisms in the ventral tegmental area contribute to nicotine addiction. Learning and Memory 2004;11:60-69. [PubMed: 14747518]

Pontieri FE, Tanda G, Orzi F, Di Chiara G. Effects of nicotine on the nucleus accumbens and similarity to those of addictive drugs. Nature 1996;382:255-257. [PubMed: 8717040] 
Pruessner JC, Champagne F, Meaney MJ, Dagher A. Dopamine release in response to a psychological stress in humans and its relationship to early life maternal care: A positron emission tomography study using [11C]raclopride. Journal of Neuroscience 2004;24:2825-2831. [PubMed: 15028776]

Rice ME, Cragg SJ. Nicotine amplifies reward-related dopamine signals in striatum. Nature Neuroscience 2004;7:583-584.

Robinson TE, Berridge KC. The psychology and neurobiology of addiction: An incentive-sensitization view. Addiction 2000;95(Suppl 2):S91-S117. [PubMed: 11002906]

Robinson S, Smith DM, Mizumori SJ, Palmiter RD. Firing properties of dopamine neurons in freely moving dopamine-deficient mice: effects of dopamine receptor activation and anesthesia. Proceedings of the National Academy of Sciences of the United States of America 2004;101:1332913334. [PubMed: 15317940]

Rosenkranz JA, Grace AA. Dopamine-mediated modulation of odour-evoked amygdala potentials during pavlovian conditioning. Nature 2002;417:282-287. [PubMed: 12015602]

Salas R, Pieri F, De Biasi M. Decreased signs of nicotine withdrawal in mice null for the beta4 nicotinic acetylcholine receptor subunit. Journal of Neuroscience 2004;24:10035-10039. [PubMed: 15537871]

Salminen O, Murphy KL, McIntosh JM, Drago J, Marks MJ, Collins AC, et al. Subunit composition and pharmacology of two classes of striatal presynaptic nicotinic acetylcholine receptors mediating dopamine release in mice. Molecular Pharmacology 2004;65:15261535.

Schultz W. Reward signaling by dopamine neurons. Neuroscientist 2001;7:293-302. [PubMed: 11488395]

Schultz W. Behavioral theories and the neurophysiology of reward. Annual Review of Psychology 2006;57:87-115.

Schultz W. Behavioral dopamine signals. Trends in Neurosciences 2007;30:203-210. [PubMed: 17400301]

Schultz W, Romo R. Responses of nigrostriatal dopamine neurons to high-intensity somatosensory stimulation in the anesthetized monkey. Journal of Neurophysiology 1987;57:201-217. [PubMed: 3559672]

Schultz W, Dayan P, Montague PR. A neural substrate of prediction and reward. Science 1997;275:15931599. [PubMed: 9054347]

Scott DJ, Heitzeg MM, Koeppe RA, Stohler CS, Zubieta JK. Variations in the human pain stress experience mediated by ventral and dorsal basal ganglia dopamine activity. Journal of Neuroscience 2006;26:10789-10795. [PubMed: 17050717]

Stolerman IP, Jarvis MJ. The scientific case that nicotine is addictive. Psychopharmacology (Berlin) 1995;117:2-10. discussion 14-20. [PubMed: 7724697]

Stolerman IP, Shoaib M. The neurobiology of tobacco addiction. Trends in Pharmacological Sciences 1991;12:467-473. [PubMed: 1792691]

Ungless MA, Magill PJ, Bolam JP. Uniform inhibition of dopamine neurons in the ventral tegmental area by aversive stimuli. Science 2004;303:2040-2042. [PubMed: 15044807]

Volkow ND, Wang GJ, Fischman MW, Foltin R, Fowler JS, Franceschi D, et al. Effects of route of administration on cocaine induced dopamine transporter blockade in the human brain. Life Sciences 2000;67:1507-1515. [PubMed: 10983846]

Volkow ND, Fowler JS, Wang GJ, Goldstein RZ. Role of dopamine, the frontal cortex and memory circuits in drug addiction: insight from imaging studies. Neurobiology of Learning and Memory 2002;78:610-624. [PubMed: 12559839]

Wang RY. Dopaminergic neurons in the rat ventral tegmental area. I. Identification and characterization. Brain Research Reviews 1981;3:123-140.

Wilson MA, McNaughton BL. Reactivation of hippocampal ensemble memories during sleep. Science 1994;265:676-679. [PubMed: 8036517]

Wise RA. Dopamine, learning and motivation. Nature Reviews 2004;5:483-494.

Wonnacott S, Kaiser S, Mogg A, Soliakov L, Jones IW. Presynaptic nicotinic receptors modulating dopamine release in the rat striatum. European Journal of Pharmacology 2000;393:51-58. [PubMed: 10770997] 
Zhang H, Sulzer D. Frequency-dependent modulation of dopamine release by nicotine. Nature Neuroscience 2004;7:581-582.

Zhou FM, Liang Y, Dani JA. Endogenous nicotinic cholinergic activity regulates dopamine release in the striatum. Nature Neuroscience 2001;4:1224-1229. 


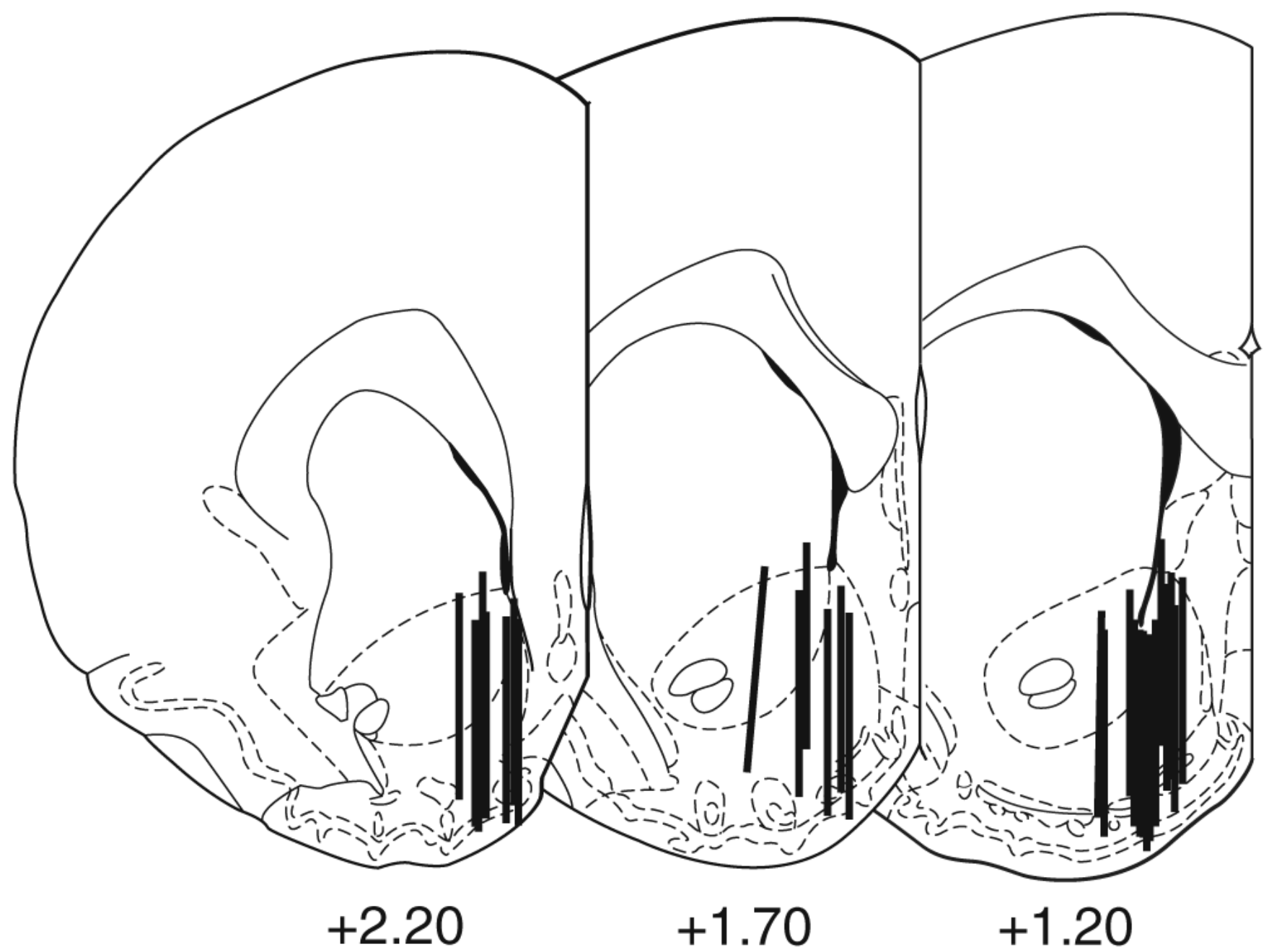

Figure 1.

Illustration showing the cannula placements for microdialysis. The coronal brain sections illustrate that all the microdialysis probe placements (black lines) are within the NAc and include the NAc shell. Numerals denote the position (in millimeters) relative to bregma. The illustration was adapted from Paxinos and Watson (1998) 

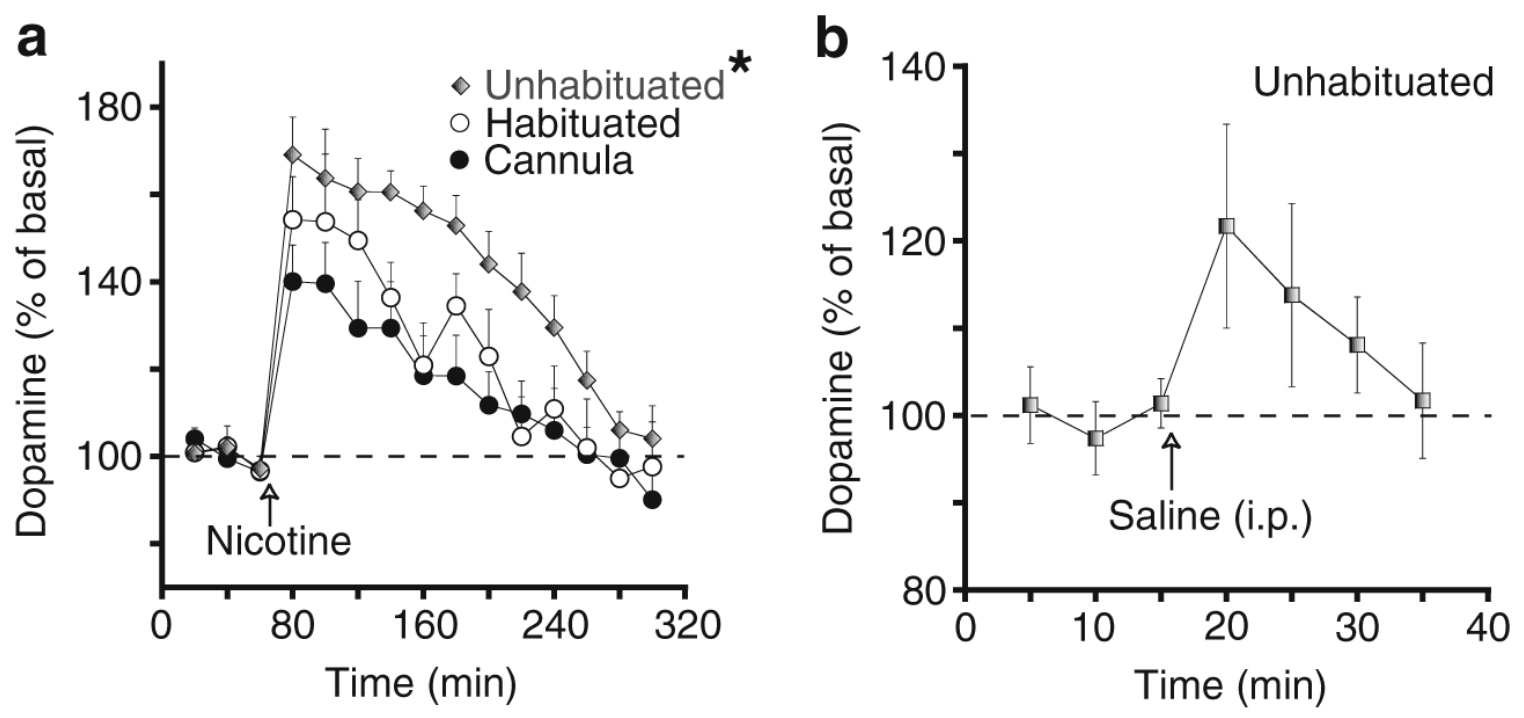

Figure 2.

Each route of nicotine administration increased the DA concentration in the NAc as measured by in vivo microdialysis. a Samples were taken every $20 \mathrm{~min}$ from freely moving rats under the following three conditions: unhabituated, naïve rats receiving i.p. needle injections ( $n=8$, diamonds), habituated rats receiving i.p. needle injections ( $n=5$, open circles), and rats receiving administration via a chronically implanted i.p. cannula $(n=10$, filled circles). The DA response in unhabituated rats was significantly different (asterisk) from that in either the habituated or the cannula group (groupxtime effect; $p<0.05$ ). b Using higher-resolution sampling ( 5 min per sample), i.p. needle injections of saline into unhabituated, naïve rats produced a small (but not statistically significant) DA signal above baseline $(n=5)$ 

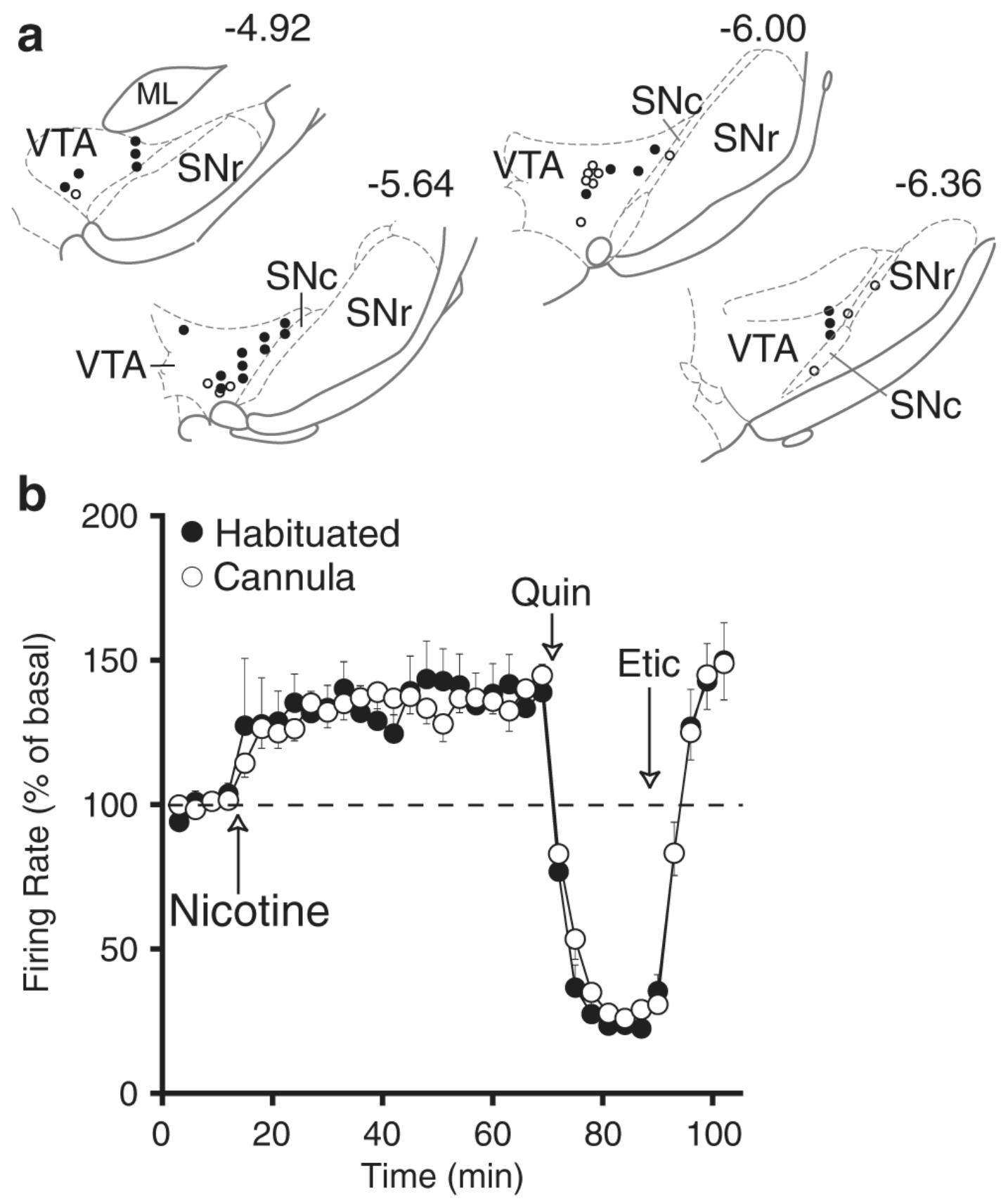

Figure 3.

Nicotine administration increased the action potential firing rate of putative DA neurons from freely moving rats (time: $F(22,748)=9.50, p<0.05)$ as measured by chronically implanted tetrodes. a The approximate recording sites within the VTA and SNc for each experimental group (open circle rats with cannula, filled circle rats habituated to the needle). Numerals denote the position (in millimeters) relative to bregma. b The normalized average firing rate of DA neurons in response to injection of nicotine, quinpirole, and eticlopride is shown from rats habituated to the needle injections ( $n=19$ units) and from rats implanted with a chronic i.p. cannula ( $n=17$ units). The illustration was adapted from Paxinos and Watson (1998) 